
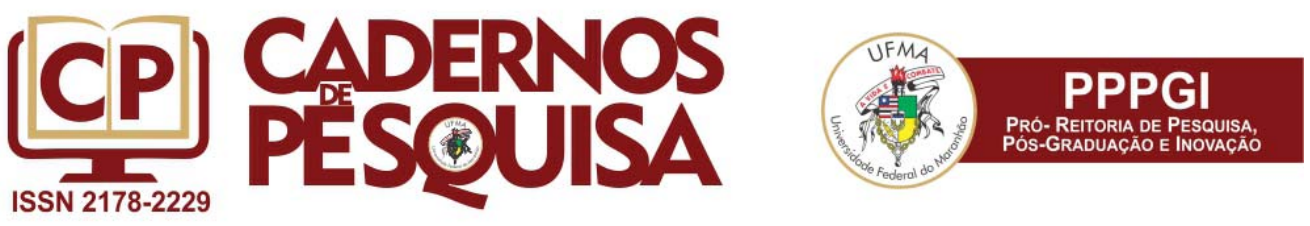

\title{
A IDEOLOGIA DA INCLUSÃO SOCIAL NO PLANO NACIONAL DE QUALIFICAÇÃO (PNQ)
}
IDEOLOGY OF SOCIAL INCLUSION IN THE NATIONAL QUALIFICATION PLAN (NQP)
LA IDEOLOGÍA DE LA INCLUSIÓN SOCIAL EN EL PLAN NACIONAL DE CALIFICACIÓN (PNQ)

\author{
Erika Porceli Alaniz \\ Professora Doutora em Educação do Programa de Pós-Graduação em Educação \\ da Universidade Estadual do Mato Grosso do Sul (UEMS). \\ Campo Grande -MS, Brasil. \\ a.porcelierika@gmail.com \\ Lúcia Bruno \\ Livre docente em Educação da Faculdade de Educação \\ da Universidade de São Paulo (USP). São Paulo -SP, Brasil. \\ lenuevo@usp.br
}

\begin{abstract}
Resumo
Discute-se, neste artigo, a concepção de inclusão social na política pública de qualificação profissional veiculada pelo Plano Nacional de Qualificação (PNQ 2003-2012). No PNQ, a dimensão 'social' tem destaque se comparado com o plano anterior, com intuito de superar as críticas do plano anterior e contemplar a minimização da pobreza como estratégia de governabilidade. Para apreendermos a contradição no discurso oficial e confrontarmos aparência e essência, realizamos a pesquisa documental e empírica que permitiu o cotejamento entre os dados coletados. Identificamos que, embora no PNQ apregoe a universalização da política de qualificação, o que se materializa é a focalização em público prioritário como, por exemplo, os pertencentes a Economia Solidária.
\end{abstract}

Palavras-chave: Qualificação Profissional. Plano Nacional de Qualificação. Política de inclusão social. Economia solidária.

\begin{abstract}
This article discussed the concept of social inclusion in the public policy of professional qualification disclosed by the National Qualification Plan (NQP-2003- 2012). In the NQP, the 'social' dimension stands out if compared with the previous plan, with the intention of overcoming the criticisms of the previous plan and, contemplate minimizing poverty as a governability strategy. To apprehend the contradiction in official speech and to confront appearance and essence, we have realized an empirical and documentary research that allowed collating between the data collected. We have identified that although the NQP proclaims the universalization of qualification policy, what is materialized is the targeting on priority public, as for instance, those belonging to the Solidarity Economy.
\end{abstract}

Keywords: Professional qualification. National Qualification Plan. Social inclusion policy. Solidarity economy.

\section{Resumen}

Se discute, en este artículo, la concepción de inclusión social en la política pública de calificación profesional transmitida por el Plan Nacional de Calificación (PNQ-2003-2012). En el PNQ, la dimensión social se destaca en comparación con el plan anterior, con el fin de superar las críticas del plan anterior y contemplar la minimización de la pobreza como estrategia de gobernabilidad. Para aprender la contradicción en el discurso oficial y confrontar apariencia y esencia, realizamos la investigación documental y empírica que permitió el cotejo entre los datos recolectados. Identificamos que, aunque en el PNQ pregona la universalización de la política de calificación, lo que se materializa es la focalización en público prioritario, como por ejemplo, los pertenecientes a la Economía Solidaria

Artigo recebido em maio 2018. Aprovado em agosto de 2018.

Cad. Pesq., São Luís, v. 25, n. 3, jul./set. 2018. 
Palabras clave: Calificación Profesional. Plan Nacional de Calificación. Política de inclusión social. Economía solidaria.

\section{INTRODUÇÃO}

O artigo analisa a concepção de inclusão social na política pública de qualificação profissional veiculada pelo Plano Nacional de Qualificação (PNQ 2003-2012), em vigência em 2017, com o objetivo de explicitar as contradições existentes entre o discurso oficial expresso nos documentos legais que regulamentam o plano em contraponto e a materialidade de sua execução. Acreditamos que o Plano Nacional de Qualificação (PNQ), introduzido no governo Lula (2003-2010) e continuado no governo Dilma Rousseff (iniciado em 2011), entre outros sentidos que possa vir a ter, um deles é promover a ideologia da inclusão social. Dizemos ideologia da inclusão, no sentido de inversão e falseamento da realidade, já que se sustenta na ideia de redução da pobreza por meio da inserção no mercado de trabalho ao mesmo tempo que a efetivação do plano apresenta possibilidade de ação cada vez mais reduzida.

Em meio aos vários aspectos de continuidade entre PLANFOR (Plano Nacional de Qualificação do Trabalhador) e PNQ, observamos nos objetivos dos planos a inclusão social com repercussão na redução da pobreza (BRASIL, 2000, 2003, 2012). Essa orientação, especificamente no PNQ, coaduna-se com a identidade que quer ser reconhecida: Plano de Qualificação Social e Profissional.

O reforço do caráter social na identidade do PNQ está amplamente difundido nos documentos legais de referência (BRASIL, 2003, 2008b), no seu atrelamento ao Plano Plurianual (2004-2007). Oliveira (2005, p.26-27) menciona que no PNQ a qualificação é afirmada na perspectiva do direito social, devendo ser objeto de uma "política nacionalmente articulada, controlada socialmente, sustentada publicamente e orientada para o desenvolvimento sustentável, para a inclusão social e para o desenvolvimento da cidadania".

Para Oliveira, essa orientação do PNQ sustenta-se em um conceito amplo de qualificação, entendido como práticas e significados socialmente construídos. Isso porque considera que a política pública de qualificação assenta-se em um novo ambiente institucional e sofre reorientação política, conceitual, institucional, ética e operacional, conforme indicado no próprio PNQ (OLIVEIRA, 2007, p.58). Moraes (2005, p. 25) também salienta esse aspecto ao afirmar que o PNQ é uma das ações políticas do governo Lula que faz parte de um programa que concebe a qualificação como uma construção social, um direito, uma política pública de inclusão social e de desenvolvimento econômico, com geração de trabalho e renda.

As afirmações anteriores (OLIVEIRA, 2005 e MORAES, 2005) apresentam apenas uma dimensão do plano: aquela como ele aparece para a sociedade, pois o PNQ e as resoluções baseadas nele confirmam esse caráter.

Art. $1^{0} \S 2^{\circ}$ - Define-se qualificação social e profissional, no âmbito desta resolução como aquela que permite a inserção cidadã no mundo do trabalho, com efetivo impacto para consecução dos objetivos descritos no Art. $2^{\circ} ;[\ldots]$

Art. $2^{\circ}$; IV - Inclusão social, redução da pobreza, combate à discriminação e diminuição da vulnerabilidade das populações; [...]. (BRASIL, 2003, p. 1).

Entendemos que essa orientação do PNQ se encontra em sintonia com os demais programas que vigoraram no governo Lula que, em contraponto à política econômica adotada, direciona ações sociais via política compensatória à população em situação de extrema pobreza com o objetivo anunciado de inserção na esfera do consumo. Esse tipo de política teve ampla divulgação naquele governo e menos no governo Dilma Rousseff, em especial no segundo mandato em que a política de ajuste fiscal e monetária adotada tem conduzido ao corte ainda mais drástico de recursos para as áreas sociais, incluindo 
os programas que repassam verbas aos setores privados até então estimulados, como é o caso do PROUNI, Minha Casa Minha Vida e Bolsa Família (CAMPOS, 2015). Ainda que não sejam esses governos e nem o anterior responsáveis por implantar políticas compensatórias e focalizadas, devemos reconhecer a abrangência que tais programas tiveram nesses governos.

As políticas compensatórias voltadas para a inserção social apresentam-se como estratégia de redução da pobreza. Entretanto, cabe considerar os aspectos históricos que conduzem ao surgimento de políticas de inserção social como substitutas das políticas de integração social. Castel (2015) menciona que a construção de uma rede mínima de seguridade social emergiu com o modelo fordista de produção, como meio de evitar a privação absoluta de benefícios fora do local de trabalho. Assim, o Estado, na versão social- democrata, é mais ou menos obrigado a oferecer o mínimo possível para assegurar a coesão social.

Com destituição da sociedade salarial como padrão hegemônico, em decorrência da reorganização do capitalismo após a crise deflagrada em 1973, modifica-se a condição de inserção da classe trabalhadora com o mundo do trabalho, que passa a caracterizarse pela proporção alarmante de desempregados, contratos por tempo determinado, precarização das condições de trabalho, fragmentação acentuada da classe e aumento da camada marginalizada em relação aos postos de trabalhos estáveis.

Nesse contexto, as políticas de integração social, que buscavam certa homogeneização das relações de trabalho e maior abrangência para o conjunto da população, como a estabelecida no âmbito do estado de bem estar social, são substituídas por políticas de inserção social, as quais obedecem a lógica de discriminação positiva e prioriza grupo sociais específicos identificados com menos possibilidades de integração social. Castel (2015) esclarece que as políticas de inserção são implementadas em uma tentativa de recuperar certo equilíbrio quando se abandona a ideia de ampla integração, mas:

[...] eis que hoje surge a suspeita de que os esforços consideráveis, que vem sendo realizados, há mais ou menos 15 anos, nessas direções, poderiam não ter, fundamentalmente, mudado a seguinte constatação: essas populações são, apesar de tudo, na atual conjuntura, inintegráveis. É essa eventualidade que deve ser encarada.

\section{MÉTODO}

Ao longo da discussão deste artigo, pretendemos demonstrar como a dimensão social propagada pelo PNQ reflete apenas a aparência, pois, ao confrontarmos com a essência, aqui entendida como a inserção na realidade, verificamos a pouca condição que tem de promover a inclusão social. Ao tratarmos da aparência e da essência, tomamos como base a discussão de Kosik (1996), ao afirmar que para apreendermos o fenômeno temos que considerar a aparência, porque é parte constitutiva dele, mas é necessário para compreendê-lo atingir a essência, pois o fenômeno só se revela na união das duas dimensões.

A pesquisa é resultado da tese de doutorado de uma das autoras do artigo e pautamo-nos na pesquisa documental e empírica com intuito de levantarmos os principais documentos orientadores da política de qualificação profissional relacionada ao PNQ, quais sejam: o Plano Nacional de Qualificação (2003-2007) (BRASIL, 2003); as principais resoluções que o regulamenta (BRASIL, 2010, 2008c); o termo de referência do PNQ (BRASIL, 2008b, 2011a).

Após a leitura e análise dos documentos, extraímos algumas ideias centrais advindas do cotejamento dos principais conceitos empregados nos documentos com a literatura especializada e referencial teórico construído. Procuramos contextualizar o discurso oficial do PNQ no cenário político contemporâneo, tanto no que se refere a configuração estrutural do capital e seu processo de mundialização quanto relacionado à 
orientação da política nacional. Assim, procedemos na construção de eixos analíticos que expressavam as contradições no discurso oficial do plano, sendo dois deles abordados a seguir: universalização versus focalização e sentido da qualidade no PNQ/PROESQ (Plano Especial de Qualificação).

Em decorrência da preocupação em abordar a contradição inerente ao fenômeno, expressa no próprio discurso oficial do PNQ e na sua efetivação ou não, procedemos a coleta de dados empíricos por meio de entrevistas semiestruturadas realizadas com gestores públicos, em especial, membros da Secretaria de Economia Solidária e do Ministério da Educação e alguns membros do movimento social denominado Rede Abelha, os quais foram executores do PNQ, na versão PROESQ. Procuramos, por meio das entrevistas, identificar o sentido da qualificação profissional direcionada aos movimentos sociais no âmbito do $P N Q$, bem como verificar as contribuições e os limites da formação oferecida para o aprofundamento nas práticas de autogestão e fortalecimento das unidades produtivas na perspectiva do trabalho associado.

Desse modo, na primeira parte do artigo, enfatizamos a pesquisa documental para, em seguida, incluir na análise alguns dados empíricos.

\section{O PNQ COMO ESTRATÉGIA DE REDUÇÃO DA POBREZA}

A orientação para a redução da pobreza é um aspecto central salientado nas recomendações advindas de organismos internacionais, como o Banco Mundial (1996), principalmente com intuito de promover a governabilidade que inclui a tentativa de inserção mínima no mercado consumidor, controle das tensões sociais por meio do oferecimento de serviços sociais a baixo custo advindos das parcerias e mobilização da comunidade e sociedade civil. Instaura-se o cenário de que o Estado não é mais o principal propositor e executor de políticas públicas, mas elas ocorrem de modo pulverizado em diferentes iniciativas promovidas no âmbito da sociedade civil, na qual o Estado aparece como ente subsidiário e não como organismo responsável pela efetivação de direitos sociais.

Brown (2009) recupera essa orientação pragmática dos organismos multilaterais aos países do primeiro e terceiro mundo no processo de globalização ao relatar que os programas monetaristas de ajuste estrutural, destinados ao combate à inflação e ao saneamento do gasto público nos setores sociais, são considerados pelo Banco Mundial e Fundo Monetário Internacional como estratégia de redução da pobreza e denominados buena gobernaza (lê-se boa governabilidade). Atender a esses imperativos demanda um conjunto de ações a serem empregadas pela sociedade civil.

\footnotetext{
La buena gobernaza es en este contexto la disciplinada aplicación de los planes de ajuste estructural ahora radicalizados y orwellianamente denominados "estrategias de reducción de la pobreza". Naturalmente, las sociedades también tienen un importante papel que desempeñar cuando el Estado ha abandonado sus políticas sociales y sus planes de desarrollo autocentrado: y los actores de la "sociedad civil" a los que constantemente se apela son Organizaciones No Gubernamentales que, intentando paliar los efectos más destructivos del sistema, se convierten en pilares del mismo, cuando no son directamente empresas privadas interesadas en el negocio humanitario. (BROWN, p. 194-195)
}

Essa orientação para redução da pobreza materializa-se, no caso brasileiro, nos vários programas do governo federal, entre eles está o $P N Q$, que a contempla em um de seus objetivos, como no art. $3^{\circ}$ (BRASIL, RESOLUÇÃO no $575,2008 b$ ). A inclusão da população vulnerável e sujeita à condição de vida miserável é um aspecto fundamental na afirmação da identidade social do plano.

A questão subjacente é que essa perspectiva de redução da pobreza ocorre em concomitância ao não atendimento de forma abrangente dos direitos sociais, entre eles o direito à qualificação para o trabalho, tal como se pode extrair da Constituição Federal de 
1988 (MACHADO, 2008). Podemos notar que muitas ações voltadas à inclusão social não são tão includentes como difunde o discurso, bem como não podem ter como horizonte a eliminação da pobreza, ainda que em longo prazo. Na verdade, são mecanismos para remediar a condição de absoluta miserabilidade que comprometeria o desenvolvimento do mercado produtivo e consumidor e impediria a reprodução ampliada do capital. Por essa razão, as políticas públicas que se destinam a reduzir a pobreza podem conviver com o desmonte dos direitos sociais conquistados pelos trabalhadores nos seus processos de luta (BOSCHESQUI; BEHRING, 2015). Cabe considerar que a consecução deste objetivo deverá ocorrer em crescente integração com outros programas do FAT, entre eles a Economia Solidária, conforme previsto no PNQ, art. $2^{\circ} \S 1^{\circ}$ (BRASIL, 2003).

Além do controle da miserabilidade explicitado no Plano, temos que considerar a inclusão da Economia Solidária no PNQ perpassada pela luta de classe, pois o trabalho associado, em especial na América Latina, tem demonstrado potencial de organização em benefício do trabalho. Vieitez e Dal Ri (2009) indicam que contingentes de trabalhadores vêm se associando com o propósito de obter o controle das unidades de produção e salvar postos de trabalho sob ameaça imediata de extinção.

No atual cenário de desemprego estrutural, as ações de formação profissional direcionadas à população vulnerável constituem-se em mecanismo de contenção da entrada da força de trabalho ao mercado e de disciplinamento. Historicamente, a expulsão do trabalho das mulheres e crianças das fábricas foi compensada com o aumento do trabalho na escola e no lar como forma de disciplinar o trabalhador (CLEAVER, 1981). Os trabalhadores excluídos do mercado de trabalho formal, que constroem estratégias de subsistência valendo-se da cooperação entre si, não estão isentos dos mecanismos disciplinares. A formação da força de trabalho, além do treinamento específico, também é um poderoso instrumento de controle.

\subsection{O PNQ enquanto política pública focalizada e a qualificação como direito social.}

Selecionamos a universalização e a focalização com o intuito de argumentar que o previsto na legislação, na sua aplicação, toma rumos bastante diferentes.

OPNQ, ao afirmar a qualificação social e profissional como direito, explicita também o caráter universalizante dessa formação. Não há a referência ao termo universalizante no PNQ, apenas na resolução que o regulamenta (BRASIL, 2008) e, nesta, não se encontra entre princípios e objetivos, mas se refere a um dos critérios para a destinação do recurso no PLANTEQ (Plano Territorial de Qualificação).

Tanto a ideia de universalização como a de focalização estão presentes no PNQ, a primeira implicitamente. Uma leitura do PNQ e das resoluções que tivesse como objetivo compreender o emprego desses termos, a princípio, poderia inferir que eles remetem a dois processos distintos, opostos e que se repelem mutuamente, pois, enquanto a universalização traz a ideia de generalização, ao ser estendida como direito a todos que demandarem, a focalização restringe, delimita e direciona o público beneficiário. Entretanto, de acordo com o Termo de Referência, as ações do PNQ devem contribuir para a gradativa universalização do direito dos trabalhadores à qualificação (BRASIL, 2008 c, p. 3). Assim posto, o plano não garante, hoje, o direito social à qualificação, mas o coloca como horizonte e, concomitante a isso, dá prioridade de acesso a determinados grupos já mencionados, indicando o caráter de complementaridade entre os termos. Essa seria a leitura oficial do plano, da sua aparência, mas para que possamos compreender o sentido dessa orientação em direção à universalização, é preciso confrontar com sua aplicação prática.

O primeiro fator que iremos considerar para demonstrar a dimensão da focalização é o custo-aluno e relacioná-lo à dotação orçamentária. O PNQ tem empregado percentuais dos recursos do FAT bem menores do que todos os anos do PLANFOR (LESSA, 2010) e, quando consideramos o custo aluno-hora, notamos pouca variação no valor, mas a ampliação da carga-horária é quase três vezes maior, o que significa, a 
princípio, maior custo de cada curso do PNQ e menor oferta de formação em relação à quantidade do público atendido.

A ampliação do custo do curso demonstra-se positiva e atende a uma das diversas críticas sofridas pelo PLANFOR, inclusive pela resolução que institui o PNQ (BRASIL, 2003). A crítica referia-se à reduzida carga-horária dos cursos, fator que, quantitativamente ampliava a oferta, mas comprometia a qualidade pedagógica. Nossa intenção é discutir como a ampliação da carga-horária do curso e, consequentemente, do seu custo ocorre em prejuízo da ampliação da oferta. Alguns autores (CASTIONI; MEDEIROS; PAULINO, 2012, p. 17) consideram que no PLANFOR, em 2000, o valormédio da hora-aula/aluno praticada em São Paulo foi de $\mathrm{R} \$ 1,90$ para uma cargahorária de 78 horas e, em anos anteriores, este custo havia sido de $\mathrm{R} \$ 2,22$, em média, para carga-horária de 70 horas. Nas parcerias com as Centrais Sindicais o contrato previa $\mathrm{R} \$ 2,40$ custo-aluno/hora para uma carga-horária de 76 horas. Se considerarmos o período de 2005-2006 no mesmo Estado, sob o governo Lula, o PLANTEQ praticou, em 2005, custo aluno/hora de $\mathrm{R} \$ 2,54$ a 2,57 para 200 horas e, em 2006, a média foi de $\mathrm{R} \$ 2,56$ e $\mathrm{R} \$ 2,57$ também para 200 horas. A média nacional correspondeu a $\mathrm{R} \$ 2,54$ para 191,10 horas em 2005, e R \$ 2,54 para 195,3 horas em 2006; e R $\$ 2,68$ para 195,3 horas em 2007 (DEPARTAMENTO INTERSINDICAL DE ESTATÍSTICA E ESTUDOS SOCIOECONÔMICOS, 2006, 2007, 2008). No caso específico da Economia Solidária, o edital de chamada pública de parcerias SPPE/MTE (BRASIL, 2008a) menciona o valor de $\mathrm{R} \$ 3,95$ a hora-aula e a carga-horária de 200 horas para atender a 30 beneficiários por curso. Tendo em vista que houve a redução da participação na qualificação profissional no total de recursos do FAT, a ampliação da carga-horária com pequena elevação do custo aluno hora-aula, certamente, indica a redução do público atendido pelo PNQ se comparado ao anterior. Oliveira (2005, p. 20) traz que, entre os anos de 1995-2005, 15,3 milhões da PEA fizeram o curso pelo PLANFOR, 88\% dos 5.547 municípios brasileiros, com investimento de 2,3 milhões. No ano de 2005, 111.430 mil pessoas cursaram os cursos do PNQ, em 2006, 112.650; em 2007, 107.953 (DEPARTAMENTO INTERSINDICAL DE ESTATÍSTICA E ESTUDOS SOCIOECONÔMICOS, 2006, 2007 , 2008). Notamos que se mantém a média de público atendido no PNQ ao longo dos três anos indicados, mas o volume do público atendido reduz-se massivamente quando comparado ao PLANFOR. Tais dados demonstram que o aumento do valor hora-aula e da carga horária dos cursos significaram a redução do público atendido, evidenciando que o discurso de universalização da qualificação profissional como direito social não se materializa.

Lessa (2010) tomou como referência o Estado do Rio de Janeiro e constatou a baixíssima abrangência do $P N Q$, apesar do discurso de universalização da educação profissional e da profissionalização em massa. A autora verificou que a proporção da população atingida pelo PNQ é muito inferior a PEA cadastrado no SINE, por exemplo, em 2006 havia uma demanda de 5.148 .710 inscritos no SINE frente a 123.645 usuários do PNQ. "[...] reafirmamos que a abrangência do PNQ está bastante aquém de suas intenções e das necessidades nacionais" (LESSA, 2010, p. 111-113). Esse fato indica a pouca veracidade do discurso da universalização do $P N Q$.

Esses dados quantitativos indicam que o PNQ não caminha para a universalização como prevê a resolução que o regulamenta (BRASIL, 2008b), mas ao restringir o público atendido, caminha em direção oposta à universalização. Nesse sentido, percebemos que o caráter de focalização do plano significa uma escolha para direcionar o recurso exíguo.

\subsection{A Economia Solidária: do PLANFOR ao PNQ}

No contexto político e econômico das décadas de 1990 e 2000, a Economia Solidária, paulatinamente, conquista destaque nos planos nacionais de qualificação profissional, em especial no PNQ, que veio à luz concomitante à criação da SENAES (SECRETARIA NACIONAL DE ECONOMIA SOLIDÁRIA). Além das experiências estaduais de política 
pública para Economia Solidária, como no Rio Grande do Sul, no governo federal, pela primeira vez iniciam programas e projetos direcionados especificamente a atender esse público.

O PLANFOR (BRASIL, 2000), o art. $8^{\circ}$ (IV; e $\S 2^{\circ}$, II) inclui entre o público alvo as pessoas que trabalham sob forma autogestionada e estabelece que uma das ações prioritárias nos Planos Estaduais de Qualificação (PEQs) serão aquelas direcionadas ao encaminhamento ao mercado de trabalho, com a inclusão das formas associativas de produção. Ao objetivar o desenvolvimento das habilidades básicas, específicas e de gestão, contempla, nas habilidades de gestão, o desenvolvimento de competências e conhecimentos relativos à autogestão. Tendo em vista essa abertura às formas de trabalho associado, algumas empresas de assessoria desenvolveram ações de qualificação nos PEQs, uma delas foi a Anteag (ASSOCIAÇÃO NACIONAL DOS TRABALHADORES E EMPRESAS DE AUTOGESTÂO E PARTICIPAÇÃO ACIONÁRIA).

Embora no PLANFOR houvesse a possibilidade de as instituições de trabalho associado executarem o plano, é no $P N Q$ que esse público, identificado pelo termo Economia Solidária, ganhar maior destaque devido, sobretudo, ao propósito de inclusão social anunciado. A orientação mais focalizada que irá predominar no $P N Q$, em certa medida, já vinha sendo assimilada desde o PLANFOR em suas versões posteriores a 1996 (ALMEIDA, 2003, p. 139), ao centrar-se no estímulo às alternativas de geração de trabalho e de integração entre as políticas que não passam pela obtenção de emprego.

\footnotetext{
No PLANFOR havia associativismo, cooperativismo e tal, mas não de forma integrada. A própria mudança do nome para plano territorial, você tem algumas adesões como a abordagem territorial do desenvolvimento. Então pra Economia Solidária isso casa como uma luva, porque a Economia Solidária ela se caracteriza como uma estratégia de dinamização econômica em processos territoriais de desenvolvimento. (MEMBRO 4 SENAES, 2011).
}

Embora seja no PNQ que a Economia Solidária ganha maior destaque, é importante ressaltarmos sua herança anterior, pois já havia o direcionamento para as políticas de emprego se voltarem à geração de trabalho e renda em abandono da ideia exclusiva de geração de emprego no mercado formal assalariado. A adesão às políticas de geração de trabalho e renda deve-se ao reconhecimento do caráter estrutural do desemprego e, por essa razão, nas últimas versões do PLANFOR esse eixo da política pública já vinha sendo contemplado. A esse respeito, França Filho (2006, p. 261) considera que a disseminação massiva de cursos de capacitação técnica objetivou o aumento da empregabilidade por meio da implementação de políticas públicas de Economia Solidária com vista ao desassalariamento da economia. Para o autor trata-se de um salto da noção de políticas de emprego para a ideia de políticas de geração de trabalho e renda.

É a partir do momento em que as políticas de emprego se voltam para a geração de emprego e renda que o PNQ enfatiza o caráter social da qualificação no seu discurso e passa a priorizar os trabalhadores em relações de trabalho informais, cooperativadas e associadas, entre outras formas de trabalho que se denominam pertencentes à Economia Solidária. Essa política encontra-se articulada a de minimização da miséria, que tem abrangência em vários ministérios parceiros do MTE/SENAES. evidente:

A ênfase do PNQ (BRASIL, 2003, p. 23) no caráter social do plano é bastante

Uma Política Pública de Qualificação, que venha a se afirmar como um fator de inclusão social, de desenvolvimento econômico, com geração de trabalho e distribuição de renda, deve nortear-se por uma concepção de qualificação entendida como construção social, de maneira a fazer um contraponto àquelas que se fundamentam na aquisição 
de conhecimentos como processos estritamente individuais e como uma derivação das exigências dos postos de trabalho [...]

Nesses termos, a qualificação social, como uma complexa construção social, inclui, necessariamente, uma dimensão pedagógica, ao mesmo tempo em que não se restringe a uma ação educativa, nem muito menos a um processo educativo de caráter exclusivamente técnico. Por outro lado, quanto mais associada estiver a uma visão educativa que a tome como direito de cidadania, mais poderá contribuir para a democratização das relações de trabalho e para imprimir um caráter social e participativo ao modelo de desenvolvimento.

Assim, a definição de qualificação social e profissional que norteia o plano é aquela que "[...] permite a inserção e atuação cidadã no mundo do trabalho, com efetivo impacto para a vida e trabalho das pessoas" (BRASIL, 2003, p. 24). Ao sobressair no discurso o caráter social do plano, busca-se, por um lado, afastar-se das noções de empregabilidade, que informava o primeiro documento do plano anterior, e de competência, ambas terminologias abolidas do documento ${ }^{1}$; por outro lado, nota-se 0 esforço de contemplar a população mais vulnerável e inseri-la no mercado de consumo de massa, em especial, pela geração de trabalho e renda, conforme indicou o PPA (2004-2007) do governo Lula. Nessa medida, a Economia Solidária, juntamente com outros programas direcionados à população pobre e vulnerável, ganha destaque nas ações focalizadas do $P N Q$, pois as iniciativas sob essa denominação destinam-se à geração de trabalho e renda; e grande parte do público que dela provém, talvez a maior parte, era composta de trabalhadores que se encontravam à margem ou estavam em condições precárias no mercado de trabalho.

Isso pode ser notado pela ideia difundida sobre o PNQ nos órgãos do governo e também presente entre os membros da Rede Abelha.

[sobre a mudança da orientação dos cursos] da nossa parte o que muda é você acentuar, por exemplo, a Economia solidária, então todos os nossos cursos começam com um módulo sobre a Economia Solidária. Isso fica muito claro para nós, porque a gente precisa divulgar o que a Economia solidária e o que pretende fazer e como as pessoas podem se inserir [...] Com relação a outros aspectos permanece a mesma coisa, a questão da prestação de contas, a questão de avaliações. (MEMBRO 1 REDE ABELHA, 2011).

Ao mesmo tempo que sobressai a discussão sobre a Economia Solidária no PNQ, o modo como os cursos são oferecidos e organizados não tem muita diferença do PLANFOR. De qualquer forma, notamos que a concepção de que o PNQ é um plano com direcionamento às questões sociais é enfatizado entre os gestores e executores da política pública. Entretanto, quando considerada sua aplicação, com base em dados qualitativos e quantitativos, notamos que o caráter social da qualificação no PNQ é pouco contemplado.

Primeiramente, consideraremos dados quantitativos extraídos do Departamento Intersindical de Estatística e Estudos Socioeconômicos (2008, p. 52) que trazem a distribuição dos educandos inscritos nos cursos do PNQ por tipo de instituição executora entre os anos de 2005-2007:

Tabela 1 - Distribuição dos educandos inscritos nos cursos do PNQ por tipo de instituição executora (\%)

\begin{tabular}{lccc}
\hline Tipo de instituição executora & 2005 & 2006 & 2007 \\
\hline Associaçãa comunitária $^{1}$ & 6,7 & 9,2 & 7,6 \\
Associação de produtores/ cooperativas & 1,8 & 1,9 & 1,2 \\
Empresariais $^{2}$ & 4,1 & 3,5 & 2,9 \\
Escolas técnicas públicas $^{2}$ & 3,8 & 2,6 & 1,8 \\
Especializadas em QSP $^{3}$ & 7,3 & 11,3 & 9,6 \\
ONGs & 19,6 & 21,5 & 23,3
\end{tabular}

\footnotetext{
Uma das dimensões do conceito competência ainda continua muito forte no PNQ, que é a ideia de validação ou certificação das competências, ainda que a lógica da empregabilidade não tenha sido abolida e tenha sido transformada na ideia de inserção pela geração de emprego e renda.
} 


\begin{tabular}{lrrr} 
Outras & 10,6 & 13,7 & 11,3 \\
Sistema S & 32,5 & 25,5 & 31,5 \\
Sindicais $^{2}$ & 8,3 & 8,0 & 7,3 \\
Ensino Superior $^{4}$ & 5,3 & 2,7 & 3,4 \\
TOTAL & 100,0 & 100,0 & 100,0 \\
\hline
\end{tabular}

(1) Inclui instituições religiosas e grupos de afinidade

(2) Inclui centrais sindicais, escolas, instituições, fundações, confederações, associações e outros.

(3) Inclui fundações, instituições e escolas

(4) Inclui universidades, institutos, faculdades e fundações.

Fonte: (BRASIL/MTE apud DEPARTAMENTO INTERSINDICAL DE ESTATÍSTICA E ESTUDOS SOCIO ECONÔMICOS, 2008)

Tabela 2 - Distribuição dos educandos concluintes nos cursos do PNQ por tipo de instituição executora -\%

\begin{tabular}{lccc}
\hline \multicolumn{1}{c}{ Tipo de instituição executora } & 2005 & 2006 & 2007 \\
\hline Associação comunitária $^{1}$ & 6,8 & 9,3 & 8,0 \\
Associação de produtores/ cooperativas $^{\text {Empresariais }}{ }^{2}$ & 1,8 & 2,0 & 1,3 \\
Escolas técnicas públicas $^{\text {Especializadas em QSP }}{ }^{3}$ & 4,1 & 3,6 & 3,0 \\
ONGs & 3,8 & 2,6 & 1,7 \\
Outras & 7,5 & 11,5 & 10,0 \\
Sistema S & 19,9 & 21,6 & 23,2 \\
Sindicais & 2 & 10,7 & 11,6 \\
Ensino Superior $^{4}$ & 31,6 & 24,6 & 30,0 \\
TOTAL & 8,4 & 8,3 & 7,7 \\
\hline
\end{tabular}

(1) Inclui instituições religiosas e grupos de afinidade

(2) Inclui centrais sindicais, escolas, instituições, fundações, confederações, associações e outros.

(3) Inclui fundações, instituições e escolas

(4) Inclui universidades, institutos, faculdades e fundações.

Fonte: (BRASIL/MTE apud DEPARTAMENTO INTERSINDICAL DE ESTATÍSTICA E ESTUDOS SOCIO ECONÔMICOS, 2008)

Tomando por base as tabelas, não temos precisão sobre qual é efetivamente o público pertencente à Economia Solidária, uma vez que na categoria ONGs podem e devem conter empreendimentos dessa natureza, além das demais instituições. Neste caso, considerar apenas os dados quantitativos seria insuficiente, por isso iremos associá-los aos dados qualitativos para compreender o alcance do atendimento do público da Economia Solidária. Mas, vale observar que a Associação de produtores/ cooperativas que, com certeza, representam o público da Economia Solidária, contam com um percentual de inscritos muito reduzido se comparado com outras instituições como as escolas do Sistema S, apesar da crítica feita pelo movimento social a essas instituições.

Além disso, temos que considerar que a demanda do público da Economia Solidária excede a capacidade de atendimento das políticas públicas, seja da SENAES seja da SPPE.

Existe a limitação, o fato de que a SPPE não consegue dar conta de todas as demandas da Economia Solidária, agora eu não saberia te dizer se isso tem a ver com o orçamento, com as vontades ou com o peso político do que está em jogo. É complicado falar! Assim o diálogo não é muito fácil, foi bem difícil conseguir o Planseq e a mais de um ano estamos tentando o terceiro [...] a gente marcou três ou quatro reuniões e eles desmarcara. É até uma reivindicação dos empreendimentos acessar mais os recursos do FAT. Quem consegue acessar com mais facilidade os recursos do FAT é o Sistema $S$, que é todo formatado pro urbano, todo formatado pra outra lógicaque já tem salas com ar condicionado e computadores [...] (MEMBRO 1 SENAES, 2011).

Nesse caso, a política focaliza apenas um dos grupos beneficiários e contempla de forma muito reduzida a Economia Solidária, apesar de difundir no plano a ideia de inserção no mercado de trabalho por meio da geração de emprego e renda e eleger esse público como prioritário. Esse fato é extremamente contraditório e revela a distância existente entre o discurso difundido pelo $P N Q$ e o que realmente se efetiva na prática social. 
Essa insuficiência das ações de qualificação para a Economia Solidária no PNQ é percebida pelos membros da SENAES, sendo até uma das razões que conduzem a Secretaria a formular um projeto próprio de formação, como o CFES (CENTRO DE FORMAÇÃO DE ECONOMIA SOLIDÁRIA), o qual busca atender ao público não devidamente contemplado nas ações de formação do PNQ, que são os formadores em Economia Solidária. Para a SENAES "[...] o que se viu é que o PNQ sozinho não dá conta, tanto que nós abrimos todas essas áreas [...]" (MEMBRO 15 SENAES, 2011).

Além do fato da Economia Solidária requerer formas de oferecimento de formação que extrapolam o previsto no $\mathrm{PNQ}$, como a formação de formadores, são os parcos recursos financeiros e o modo como se opera o financiamento no Estado, os maiores limitadores na execução das ações de formação:

\begin{abstract}
[...] obviamente nós fazemos planos e entram recursos próprios do orçamento das SENAES e entram recursos da SPPE, assim os dois lados decidem cada um o quanto podem dispor para esta atividade e pelo o que eu tinha percebido a demanda é muito maior do que nós conseguimos atender. Fizemos uma audiência no ano passado e apareceu grande número de pessoas com projetos de formação profissional em Economia Solidária, eles colocam os números de vagas que precisariam para que os seus projetos sejam executados, tudo somou 80.000, o que fica completamente fora das nossas possibilidades, tanto nossas como as da SPPE, então existem intenções orçamentárias dentro do Ministério é inegável que exista, a maneira do orçamento ser planejado e executado eu diria que é quase caótica no governo federal. (MEMBRO SENAES, 2011).
\end{abstract}

Com base na citação acima, notamos a dificuldade de se constituir o propósito de universalização expresso no plano, ao contrário, ele demonstra ser insuficiente no atendimento do público da Economia Solidária que tem solicitado por políticas públicas de formação. Além disso, a inadequação dele ao público prioritário é outro fator que demonstra os limites de expansão em direção ao cumprimento dos direitos sociais desse público anunciados no PNQ.

Outro aspecto que aponta o pouco direcionamento do plano para o público da Economia Solidária refere-se às orientações do PNQ na execução do convênio. O plano não prevê as condições de trabalho próprias do público da Economia Solidária e, dessa forma, as normas de execução do plano são construídas de modo a privilegiarem as instituições que apresentam melhor infraestrutura e são mais formalizadas. Por essa razão, muitas instituições, como o Sistema S, por exemplo, aparecem como os mais aptos a executar o PNQ, e aquelas que são próprias do trabalho associado tendem a ser excluídas do processo.

A esse respeito, os entrevistados dizem que o recorte do PNQ para Economia Solidária não contempla sua especificidade, pois não há diretrizes e orientações do PNQ que levem em consideração a forma de organização e necessidades do empreendimento, uma vez que a excessiva burocratização dificulta a execução das ações:

[..] Por incrivel que pareça se acumulou experiência, mas se tem dificuldades em justificar nossas especificidades e isso se deve a um choque de culturas. A cultura do PNQ é da empregabilidade, então você qualifica, registra e comprova a empregabilidade [...] Ás vezes, não se consegue justificar, sobretudo, quando se muda a área técnica - os novos técnicos que acompanham têm dificuldade em entender essas especificidades; segundo, pela realidade das executoras. Uma coisa é o padrão SEBRAE, SENAC, SENAE, normalmente você tem uma sala de aula com ar refrigerado, $O$ aluno recorre ao curso porque é um atrativo de acordo com 0 curso oferecido. Em Economia solidária é totalmente diferente: você vai trabalhar com pessoas muito pobres, às vezes, muito desmotivados. (MEMBRO 4 SENAES, 2011).

A questão que queremos evidenciar refere-se ao fato do PNQ não ter previsto as características de seu público prioritário, que deveria ser o foco privilegiado do financiamento. Desse modo, podemos notar a pouca adequação à realidade dos 
empreendimentos de Economia Solidária, ainda que a presença desse segmento sirva para reforçar o caráter social do plano. No Seminário Nacional de Sistematização (2008, p. 1) há a afirmação de que o PLANSEQ indica a "[...] modalidade 'social' do $P N Q$ e objetiva desenvolver processos educativos de qualificação social e profissional voltados para os trabalhadores das redes de cooperação econômica e solidária". Essa contradição mostra como as ideias expressas no plano difere significativamente daquilo que se materializa pela ação.

Do ponto de vista do Estado, um plano de qualificação em massa que se identifique como social tende a ter grande penetração junto à população e mesmo nos movimentos sociais, além de ser instrumento importante na estratégia de governabilidade. Essa busca de aceitação ocorre justamente no momento em que houve expressiva redução de recursos para essa finalidade, como indicado. E, também, num momento em que o trabalho associado ganha expressão no cenário internacional, em especial, entre os países latino-americanos. Trata-se de experiências originais dos trabalhadores em direção a sua sustentabilidade e auto-organização, independentes das formas clássicas de controle do capital. Parece-nos que o Estado recorre à estratégia que Souza (2010) observa na dinâmica do capitalismo quando este assimila as ideias que desfrutam de prestígio e poder de persuasão para ganhar penetração social em um momento de importante crise de acumulação do capital.

No caso do PNQ, a utilização de terminologias e ideias com grande penetração social parece ter o propósito de garantir a governabilidade, tendo em vista as orientações dos organismos multilaterais de buena gobernanza (BROWN, 2009), como discutimos. As intenções tornam-se ainda mais evidentes quando o consideramos como construção do governo Lula, o qual se difunde como um governo que priorizou a questão social, inclusive, sustentado na trajetória do Partido dos Trabalhadores (PT).

\subsection{Controvérsia no sentido da qualidade avaliada no PNQ}

O segundo fator refere-se à avaliação e ao controle do PNQ sobre a qualidade pedagógica das ações desenvolvidas. Está previsto que a avaliação e o controle devem garantir a efetividade social, a qualidade pedagógica e a eficácia das ações previstas (BRASIL, 2003).

O Termo de Referência do PNQ (BRASIL, 2008c, p. 6)² define qualidade pedagógica com base em alguns indicadores, tais como: forma de oferecimento do curso (cursos presenciais, à distância, laboratórios, seminários, oficinas, assessoria, extensão, pesquisas, estudos, entre outras); conteúdos básicos, obrigatórios e específicos; cargahorária como instrumento para assegurar a qualidade pedagógica das ações de 200 horas (sendo $85 \%$ de cursos ou laboratórios com carga-horária igual ou superior a 40 horas e até $15 \%$ com carga-horária igual ou superior a 16 horas em seminários, oficinas). Consideram, ainda, que na organização dos cursos:

\footnotetext{
[...] preferencialmente, serão tomados como base, tendo como referência as atividades humanas e o desenvolvimento científico e tecnológico, ou itinerários formativos, entendidos como possibilidades de percurso que compõem a educação profissional e tecnológica, possibilitando o aproveitamento contínuo e articulado dos estudos; ou arcos ocupacionais, entendidos como conjunto de ocupações relacionadas, dotadas de base socio-técnica comum, garantindo uma formação mais ampla e aumentando as possibilidades de inserção ocupacional. (BRASIL, 2011b, p. 7).
}

Ao confrontarmos com a avaliação realizada em 2010 pelo DEQ/SPPE/MTE ${ }^{3}$ sobre as entidades de Economia Solidária que desenvolveram o PLANSEQ/PNQ, oficina de bordado e pintura do tecido, identificamos que a carga-horária se sobressai como indicador da qualidade do curso.

\footnotetext{
Este termo de referência sofreu atualização em 29.09.2011, aprovado pela Res. $n^{\circ}$ 679/2011. Contudo, como estamos discutindo princípios gerais do PNQ não nos referimos, especificamente, a esse documento.

Pautaremo-nos no relatório técnico de supervisão elaborado pelo DEQ/SPPE/MTE em 2010 (MEMO № 4561).
}

Cad. Pesq., São Luís, v. 25, n. 3, p. 11-28, jul./set. 2018. 
Um dos indicadores utilizados como parâmetro de avaliação do programa, tanto para efeito de execução quanto para o fechamento da prestação de contas, é a qualidade pedagógica do curso. Nesses termos, ressaltamos a importância de se observar/ acompanhar toda a execução do curso se a carga-horária estabelecida está sendo devidamente cumprida (horário de realização do curso). Note-se ainda que um educando só pode ser considerado concluinte quando atingir $75 \%$ da presença total da ação. (RELATÓRIO..., 2010).

Podemos observar a importância atribuída à carga-horária como indicador da qualidade pedagógica. Entendemos que o indicador carga-horária e horário de realização do curso são insuficientes para averiguar a qualidade pedagógica de uma ação. Apesar de o documento assinalar que ele não é único indicador e que há outros, percebemos que os demais se referem, também, a aspectos relacionados à organização formal das ações, além de serem pouco relevantes para se avaliar a qualidade pedagógica. Neste caso, é importante indicarmos quais são os critérios valorizados na avaliação do DEQ/SPPE/MTE. A totalidade dos aspectos avaliados, mediante questionário padronizado, indica que os principais problemas encontrados na avaliação referem-se a: infraestrutura; ausência de logomarca do PNQ no local onde se realizava o curso; ausência de recebimento do vale-transporte com assinatura diária dos educandos; número de educandos em sala inferior ao planejado; ausência de lista de presença com assinatura dos educandos, portanto, fora dos padrões exigidos pelo programa; ausência de comprovante de recebimento de material didático; e ausência de lista de recebimento de lanche. A avaliação do conteúdo do curso é abordada de forma genérica: há uma questão relacionada ao grau de satisfação do educando, outra sobre a importância dos conteúdos para formação profissional e o cumprimento da parte teórica e prática nos cursos. Há, também, oito questões destinadas aos educadores que se relacionam ao cumprimento do programa, atendimento dos objetivos e metodologia adequada. Ao final, a equipe avaliadora sugere o cumprimento das normas de padronização dos instrumentos.

É evidente que a avaliação em política pública deva questionar-se acerca da execução das ações, tendo em vista a aplicação dos recursos conforme previsto, mas a avaliação da qualidade pedagógica não pode esgotar-se nesses aspectos pouco relevantes. É fundamental correlacionar os conteúdos ministrados com a inserção no mundo produtivo que se pretende viabilizar, para que a avaliação possa constituirse em um instrumento para refletir sobre a adequação da política pública que se faz. Neste caso, notamos que as questões relacionadas especificamente aos conteúdos são questionadas de modo superficial ao voltarem-se apenas para as expectativas dos alunos, a compreensão das aulas e ao trabalho do professor com ênfase nas técnicas de ensino utilizadas.

Notamos que o eixo tecnológico ou de base sociotécnica, bem como a continuidade e o aprofundamento dos estudos que devem ser o eixo da formação, sequer são questionados ou suscitam sugestões da equipe técnica a esse respeito. Esse seria um aspecto realmente importante, uma vez que, além de ser um eixo estruturante da formação, indicada no Termo de Referência, é também, na sociedade contemporânea, requisito importante para inserção do trabalhador em qualquer organização produtiva, em especial, naquelas da denominada Economia Solidária, em que o desenvolvimento de tecnologias condizentes com os processos autogestionários é urgente. Não contemplar essa dimensão tende a ocasionar o arrefecimento das experiências de autoorganização dos trabalhadores e de seus empreendimentos, bem como contribui na reprodução das relações de trabalho típicas do capitalismo.

Nessa perspectiva, o curso não contribui para uma inserção tecnológica ou formação com base técnica e científica difundidas pelo plano, ao contrário, trata-se de uma adaptação às condições de vida da população atendida. Mesmo as tecnologias capitalistas não estão contempladas no curso de bordado e pintura sob a orientação do PNQ que, neste caso, seriam tecnologias na área da moda e designer de produtos. 
Ainda que não atendesse às necessidades do trabalho associado, ao menos seria mais coerente com o desenvolvimento científico e tecnológico previsto no Plano e teria em vista agregar mais valor ao trabalho devido à característica de trabalho complexo. Nesse caso, a avaliação que a SPPE faz do PLANSEQ/PNQ para Economia Solidária desconsidera a adequação do plano às especificidades da organização do trabalho associado, autogestão, entre outros aspectos que se referem a um plano alternativo de comercialização e consumo, tendo em vista a construção de outro projeto de sociedade.

Mészáros (2002) menciona que construir outro projeto de sociedade pressupõe o controle global do processo de trabalho pelos produtores associados e não simplesmente a subversão dos direitos de propriedade estabelecidos, pois apenas "a expropriação dos expropriadores" não é suficiente para realizar o feito de caminhar em direção à construção da sociedade socialista. Tais questões sequer são mencionadas no Relatório de avaliação, portanto averiguar se ocorre e o modo como é desenvolvida a formação sociotécnica não se constituem preocupação por parte dos órgãos governamentais, ainda que esteja previsto no $P N Q$.

Essa forma de proceder na avaliação, cujo centro da preocupação é o cumprimento dos aspectos formais, sendo desconsiderados os aspectos que permitiriam investigar a relevância da ação desencadeada, reflete a operacionalidade da burocracia que, como diz Tragtenberg (2006), apesar de racional na área administrativa, torna-se irracional na área das decisões políticas. Isso porque o Estado burocrático fundamenta-se em interesses que são contrários aos direitos sociais da classe trabalhadora. A burocracia consolida-se na linguagem técnica, nas credenciais que justificam os cargos nos órgãos governamentais e na objetividade com que procura coletar e analisar os dados obtidos da realidade, entre outros aspectos. Desse modo, a avaliação da política implementada, revestida de caráter técnico-administrativo, pouco informa sobre o alcance da formação viabilizada pelo $P N Q$ e, na verdade, não problematiza aspectos fundamentais como a formação profissional dos trabalhadores da Economia Solidária e sua relação com a adequação sociotécnica decorrente do desenvolvimento de tecnologias sociais.

A ausência de uma avaliação de caráter qualitativo que pudesse acompanhar o processo de formação e suas implicações na sociedade é identificada por uma das gestoras públicas entrevistadas ao ser questionada sobre os desafios enfrentados na formação de formadores para a Economia Solidária:

\footnotetext{
Desafios são avançar na discussão. Se formos avaliar, temos que considerar o que foi produzido como material, quais as possibilidades, resultados, como que as pessoas do projeto perceberam, aproximaram-se, construíram conjuntamente algo. É a partir de uma avaliação disso que podemos ver o que está faltando. $O$ desafio é avaliar qualitativamente, capilarizar as ações, porque nós temos os projetos, mas é pouco perto de um país dessa dimensão. (MEMBRO MEC, 2011).
}

Avaliar as implicações sociais das ações não se constitui em objetivo a ser perseguido nos documentos de avaliação dos projetos desenvolvidos no âmbito do $P N Q$, especialmente quando consideramos o que buscam captar com os instrumentos utilizados. Isso acontece, embora técnicos da SPPE acompanhem a execução das ações com o objetivo de fiscalizar e avaliar o andamento, como podemos observar:

\footnotetext{
No PLANSEQ II, o convênio foi feito diretamente com as entidades - num total de sete convênios - e quem acompanhou foi a SPPE e eu pela SENAES. Nesse PLANSEQ já não teve pessoa pra sistematizar tudo em um documento, mas a gente teve um seminário, em dezembro de 2010 no Rio de Janeiro, e todas as redes participaram e cada rede tentou levar um educador, um educando e uma pessoa que coordenou a parte mais pedagógica, dentro do possível de três a quatro pessoas de cada rede participaram [...] as redes apresentaram em power point os desafios e as dificuldades,
} 
os educandos colocaram também sua experiência. Teve esse momento de avaliação, mas não houve sistematização disso em um livro. (MEMBRO 1 SENAES, 2011)

No âmbito dos projetos PROESQ e PLANSEQ do PNQ desenvolvido pela Rede Abelha, houve, no decorrer das atividades pedagógicas, avaliações das atividades desenvolvidas e, em alguns desses momentos, estavam presentes a SENAES e a SPPE, conforme indicam os entrevistados. Notamos que a forma de avaliar da SPPE desconsidera as avaliações processuais realizadas pelas entidades executoras do $P N Q$, ao não levar em conta os dados que poderiam servir de parâmetro para verificar a qualidade dos cursos. A avaliação do PROESQ e PLANSEQ realizados pela Rede Abelha poderia constituir-se em um dado relevante a ser considerado pela política pública em questão, uma vez que tinha como objetivo verificar a inserção dos educandos em atividades produtivas, em associações e grupos produtivos. De acordo com uma das entrevistadas, estes critérios permitem dimensionar os impactos das ações educativas nas comunidades e na vida desses/as trabalhadores/as.

A validação é algo fundamental porque o material didático para ser impresso, ele precisa ser conhecido, precisa ser testado para ser impresso e ser levado adiante [as avaliações no projeto Proesq] eram de avaliação do material didático, era um momento de avaliação do curso, da prática que tinham exercido [...] É a mesma coisa das roupas, das vestimentas, então se produz uma vestimenta e depois o apicultor diz essa vestimenta é muito quente, então a vestimenta é colocada à prova, outros dizem o que é que podemos fazer até chegar num modelo que possa atender aos interesses do apicultor. (MEMBRO 6 REDE ABELHA, 2011).

Embora o PNQ explicite necessidade de uma avaliação qualitativa no PROESQ, a SPPE não a pratica.

Art. 17. O PNQ deverá ser avaliado e controlado, de modo a garantir a efetividade social, a qualidade pedagógica, eficiência, eficácia das ações previstas, além da transparência e lisura na aplicação dos recursos.

$\S 1^{\circ} \mathrm{O} P N Q$ disporá de um sistema integrado de planejamento, monitoramento e avaliação (SPMA) envolvendo um processo permanente de acompanhamento de ações iniciadas na execução de projetos especiais de qualificação com o objetivo de: $[\ldots]$

II- Sistematizar as informações mais relevantes produzidas por esses mecanismos e instâncias;[...]

IV- Construir um conjunto de indicadores de Efetividade Social e Qualidade Pedagógica para análise dos programas e projetos de qualificação; [...]

$\S 2^{\circ} \mathrm{O}$ sistema PMA deverá promover o constante aperfeiçoamento do PNQ nas seguintes dimensões:

I-A dinâmica do Plano Nacional de Qualificação e seus impactos nos planos territoriais e projetos especiais;

II-A especificidades e iniciativas inovadoras dos planos territoriais e projetos especiais; $[\ldots]$

IV- A gestão pedagógico-metodológica;

V- Os impactos do Programa Nacional de Qualificação para os trabalhadores envolvidos.

VI- A integração do Programa Nacional de Qualificação com políticas públicas de geração de emprego e renda, educação e desenvolvimento socioeconômico.[...]

$\S 5^{\circ}$ O SPMA contribuirá para que a avaliação no âmbito do PNQ apresente enfoque qualitativo, inserido em uma perspectiva transformadora das práticas e da realidade; comprometimento com o "direito à informação" para os participantes 
dos programas que estão sendo avaliados e demais públicos interessados. (BRASIL, 2003, p. 22-23, grifos nossos).

Diante dos compromissos firmados no PNQ fica ainda mais evidente a insuficiência dos critérios considerados na avaliação realizada pela SPPE. A forma de proceder na avaliação, à primeira vista, revela as prioridades da política pública de qualificação profissional, mas é necessário ainda nos questionarmos sobre o que elas representam e como configura-se o Estado que materializa tal política pública.

Para aprofundarmos essa discussão é preciso termos clareza acerca do papel do Estado liberal. Marx (1993), em um belíssimo texto no qual analisa a "Questão Judaica", explica que ocorre a emancipação política quando o Estado se torna Estado político, a partir desse momento secundariza a teologia, torna-a independente do Estado e a transfere à vida privada. Mas, ao emancipar-se politicamente, o homem emancipa-se de modo desviado porque o intermediário da emancipação é o Estado, sendo assim, o homem é libertado da religião para ser tutelado pelo Estado. A partir disso, reconhece a si mesmo por meio do Estado, pois "É o Estado o intermediário entre o homem e liberdade humana" (MARX, 1993, p. 43) a quem o homem confia toda sua liberdade.

O Estado passa a ser o guardião da liberdade do homem considerado como indivíduo com prerrogativas de direito (MARX, 1993). Surge, com o Estado de assuntos gerais da vida pública, a dissolução da sociedade civil nos elementos simples em que, de um lado, está o indivíduo egoísta, de outro, uma série de elementos materiais e culturais convertidos em direitos. Valendo-se dessa configuração do Estado político é que ele pode proclamar a universalidade dos direitos aos membros da sociedade civil, uma vez que as diferenças sociais são delegadas à vida privada, portanto, preservadas. Assim, o Estado elimina a relação direta entre o usufruto do poder político baseado na diferença de posição social, no nascimento, na educação e na profissão, porque transfere tais diferenças à esfera privada da sociedade civil, na qual o homem se relaciona com outro ser social real. Feito isso, pode proclamar a universalidade: "Unicamente assim, por cima dos elementos particulares, é que o Estado se constitui como universalidade" (MARX, 1993, p. 46)

O homem, na sua realidade mais íntima, na sociedade civil, é um ser profano. Precisamente aqui, onde aparece a si mesmo e aos outros como indivíduo real, surge como fenômeno ilusório. Em contrapartida no Estado, onde é olhado como ser genérico, o homem é o membro imaginário de uma soberania imaginária, despojado da sua vida real, individual, e dotado de uma universalidade irreal. (MARX, 1993, p. 46).

Assim, embora a emancipação política tenha avançado em relação às formas anteriores, não é a emancipação real, pois se trata de uma da ideia abstrata de universalidade ao ignorar as condições sociais concretas que define cada ser social e preservar as diferenças efetivas entre os homens. Por essa razão, os documentos legais podem pressupor a universalidade dos direitos, avançar em vários aspectos da regulamentação da vida política, já que se afasta e preserva as desigualdades sociais e as relações concretas que os homens estabelecem entre si.

Essa discussão é importante porque mostra o descompasso entre a realidade material e a configuração do Estado político e, ao fazer isso, evidencia que não se trata apenas de fazer cumprir a lei, o que já seria muito importante. Mas, de compreender que os direitos universais, que fundamentam os documentos legais no Estado liberal, são abstrações que não podem ser alcançadas na plenitude.

Retomando a discussão específica do PNQ à luz dessa fundamentação, podemos observar que o documento estabelece direitos além do que consegue materializar; com isso, sinaliza a dificuldade de atingir tais prerrogativas. Por essa razão, a avaliação como um de seus instrumentos de controle, preocupa-se com os aspectos mencionados e não com o alcance e a execução qualitativa da política. 


\section{CONSIDERAÇÕES FINAIS}

O Estado configura-se como instrumento de poder político do capital (MÉSZÁROS, 2002), portanto as políticas públicas no interior desse aparato tendem a encontrar limites para se desenvolverem. Por essa razão, a ideia de universalização dos direitos sociais e, nesse caso, do direito à qualificação encontra dificuldade para se efetivar e generalizar ao conjunto da sociedade.

Muitas vezes, quando alguns direitos sociais são ampliados há prejuízo na qualidade do atendimento prestado. Nesse caso, o PNQ é emblemático, pois apesar do discurso da qualificação como direito social dos cidadãos brasileiros contida no plano, tal política pública defronta-se com vários desafios na sua efetivação.

Ainda que esteja prevista a universalização do direito à qualificação no $P N Q$, ao confrontarmos com a execução do plano, constamos o movimento inverso, ou seja, ele tem se caracterizado pela redução abrupta e significativa de recursos se comparado ao plano anterior (PLANFOR) e atendido uma parcela restrita da população. Embora, no discurso, a política focalizada seja concebida como estratégia para priorizar o público excluído de modo a universalizar o direito, na execução do PNQ, notamos que é uma opção feita em decorrência da pouca condição de expandir as ações de qualificação em razão da insuficiência de recursos e da atuação cada vez mais restrita do Estado brasileiro nas áreas sociais.

\section{REFERÊNCIAS}

ALMEIDA, M. L. Da formulação à implementação: análise das políticas governamentais de Educação profissional no Brasil. 2003. Tese (Doutorado em Política Científica e Tecnológica)Instituto de Geociência, Universidade Estadual de Campinas, Campinas, 2003.

BANCO MUNDIAL. Prioridades y estratégias para la educación: examen Del Banco Mundial. Washington, EUA: Banco Internacional de Reconstrucción, 1996.

BEHRING, E. R; BOSCHETTI, I. Política social: fundamentos e história. 9. ed. São Paulo: Cortez, 2015. v. 2.

BRASIL. Ministério do Trabalho e Emprego. Edital da Chamada Pública no 11/2008: Plano Setorial de Qualificação - Anexo II-B. Brasília, DF: MTE, 2008a.

. Ministério do Trabalho e Emprego. Secretaria de Políticas Públicas de Emprego. Departamento de Qualificação. Plano Nacional de Qualificação - Termo de Referência. Brasília: TEM; SSPE; DEQ, 2008b.

. Resolução CODEFAT n $n^{\circ} 258$, de 21 de dezembro de 2000. Estabelece critérios para transferência de recursos do Fundo de Amparo do Trabalhador - FAT, ao Plano Nacional de Qualificação do Trabalhador - PLANFOR. Diário Oficial da União, Brasília, DF, 28 dez. 2000. Seção 1, p. 116-118. Disponível em: <http://portalfat.mte.gov.br/wp-content/uploads/2016/01/Resolução-no-258-de-21-de-dezembro-de-2000.pdf >. Acesso em: 01 jun. 2011.

Resolução CODEFAT n 333, de 10 de julho de 2003. Institui o Plano Nacional de Qualificação - PNQ e estabelece critérios para transferência de recursos do Fundo de Amparo ao Trabalhador - FAT ao PNQ. Diário Oficial da União, Brasília, DF, 14 jul. 2003. Seção 1, p. 64-67. Disponível em: <http://portalfat.mte.gov.br/wp-content/uploads/2016/01/Resolução -no-333-de-10-de-julho-de-2003.pdf>. Acesso em: 20 dez. 2010.

Resolução CODEFAT n ${ }^{\circ} 575$, de 28 de abril de 2008. Estabelece diretrizes e critérios para transferências de recursos do Fundo de Amparo do Trabalhador - FAT, aos estados, municípios, organizações governamentais, não governamentais ou intergovernamen- 
tais, com vistas à execução do Plano Nacional de Qualificação - PNQ. Diário Oficial da União, Brasília, DF, 02 maio 2008c. Disponível em: <http://portalfat.mte.gov.br/wp-content/ uploads/2016/01/Res575.pdf>. Acesso em: 20 dez. 2010.

Resolução nº38 de 12 de abril de 2010. Brasília: MTE, SPPE, 2010.

Resolução CODEFAT $n^{\circ}$ 672, de 28 de julho de 2011. Modifica a Resolução $n^{\circ} 575$, de 28 de abril de 2008, incorporadas as alterações efetuadas por resoluções subsequentes, e o Termo de Referência aprovado na Resolução n 667, de 26 de maio de 2011. Diário Oficial da União, Brasília, DF, 01 ago. 2011a. Seção 1, p. 105-106. Disponível em: <http://portalfat. mte.gov.br/wp-content/uploads/2016/01/Res672.pdf >. Acesso em: 23 maio 2017.

Resolução CODEFAT n 679, de 29 de setembro de 2011. Estabelece diretrizes e critérios para transferências de recursos do Fundo de Amparo ao Trabalhador - FAT, aos estados, municípios, organizações governamentais, não governamentais ou intergovernamentais, com vistas à execução do Plano Nacional de Qualificação - PNQ. Diário Oficial da União, Brasília, DF, 03 out. 2011b. Seção 1, p. 131-139. Disponível em: <http://portalfat.mte.gov.br/ wp-content/uploads/2018/04/Res679_2011-_-Critérios-PNQ-e-anexo-Termo-de-Referência. pdf>. Acesso em: 23 maio 2017.

Resolução CODEFAT n 696, de 28 de junho de 2012. Altera a Resolução $n^{0}$ 679, de 29 de setembro de 2011, que estabelece diretrizes e critérios para transferências de recursos do Fundo de Amparo ao Trabalhador - FAT, aos estados, municípios, organizações governamentais, não governamentais ou intergovernamentais, com vistas à execução do Plano Nacional de Qualificação - PNQ. Diário Oficial da União, Brasília, DF, 02 jul. 2012. Seção 1, p. 131-138. Disponível em: <http://portalfat.mte.gov.br/wp-content/uploads/2018/04/Res696 2012-_-Altera-Res679_2011-e-aprova-novo-Termo-de-Referência.pdf>. Acesso em: 23 maio 2017.

BROWN, J. La dominación liberal: ensayo sobre el liberalismo como dispositivo de poder. Madrid: Tierradenadie, 2009.

CAMPOS, V. Alicerces abalados: habitação- o setor símbolo da inclusão social sofre com as políticas do governo, recebe recursos, mas o horizonte continua nebuloso. Carta Capital, São Paulo, ano 21, n. 854, p. 44, jun. 2015.

CASTEL, R. As metamorfoses da questão social: uma crônica do salário. 12. ed. Petrópolis: Vozes, 2015.

CASTIONI, R.; MEDEIROS, I. A. de; PAULINO, L. A. As tentativas de "enquadrar" a oferta de cursos de qualificação no âmbito do PLANFOR: a experiência de São Paulo. São Paulo, [200-]. Disponível em: <http://www.fe.unb.br/quem-e-quem/docentes/r/remi/publicacoes/10_Experiencia_SERTSP_ PEQ.pdf>. Acesso em: 23 jan. 2012.

CLEAVER, H. Leitura política do capital. Rio de Janeiro: Zahar, 1981.

DEPARTAMENTO INTERSINDICAL DE ESTATÍSTICA E ESTUDOS SOCIOECONÔMICOS. Anuário de qualificação social e profissional: 2006. São Paulo: DIEESE, 2006.

Anuário de qualificação social e profissional: 2007. São Paulo: DIEESE, 2007. Anuário de qualificação social e profissional: 2008. São Paulo: DIEESE, 2008.

FRANÇA FILHO, G. C. Avaliação de políticas de economia solidária no Brasil. In: FRANÇA FILHO, G. C. et al. Ação pública e economia solidária: uma perspectiva internacional. Porto Alegre: Editora UFRGS, 2006. p. 259-268. 
KOSIK, K. Dialética do concreto. 4. ed. Rio de Janeiro: Paz e Terra, 1996. p. 9-51.

LESSA, S. E. C. A sofisticação da aprendizagem simples e a abordagem da pobreza: políticas de formação para o trabalhador pobre. 2010. Tese (Doutorado em Serviço Social)- Universidade Federal do Rio de Janeiro, Rio de Janeiro, 2010.

MACHADO, L. R. S. A carta de 1988 e a educação profissional e tecnológica: interpretação de um direito e balanço aos vinte anos de vigência. Competência - Revista da Educação Superior do SENAC-RS, Porto Alegre, v. 1, p. 11-28, 2008.

MARX, K. A questão judaica. In: Manuscritos econômicos: filosóficos. Lisboa: Edições 70, 1993. p. 35-76.

MÉSZÁROS, I. Para além do capital. São Paulo: Boitempo, 2002.

MORAES, E. L de. Relação gênero e raça na política pública de qualificação profissional. Brasília, DF: TEM; SPPE; DEQ, 2005.

OLIVEIRA, R. V. de. A qualificação profissional como política pública. Brasília, DF: TEM; SPPE; DEQ, 2005. v. 3.

Momento atual da política pública de qualificação profissional no Brasil: inflexões e desafios. Árius, Campina Grande, v. 13, n. 1, p. 121-132, jan./jun. 2007.

RELATÓRIO de Supervisão Técnico e Nota Administrativa. Memo no 4561 / DEQ / SPPE / MTE. [S.I.]: TEM; SPPE; DEQ, 2010. p. 7-8.

SEMINÁRIO NACIONAL DE SISTEMATIZAÇÃO. Plano Setorial de Qualificação Social e Profissional. Brasília: MTE/SPPE/DEQ, 2008.

SOUZA, J. Os batalhadores brasileiros: nova classe média ou nova classe trabalhadora? Belo Horizonte: Editora da UFMG, 2010.

TRAGTENBERG, M. Burocracia e ideologia. 2. ed. São Paulo: Editora UNESP, 2006.

VIEITEZ, C. G.; DAL RI, N, M. Mudança social na América Latina: trabalho associado e educação. Araraquara: Junqueira \& Marins, 2009. 